\title{
Prophylactic Treatment with Cerium Oxide Nanoparticles Attenuate Hepatic Ischemia Reperfusion Injury in Sprague Dawley Rats
}

\author{
Nandini D.P.K. Manne ${ }^{a, b}$ Ravikumar Arvapallia Vincent A. Graffeo ${ }^{c, d}$ \\ Venkata V. K. Bandarupallia Tolou Shokuhfare Sweetu Patele Kevin M. Rice ${ }^{a}$ \\ Gautam Kumar Ginjupallia Eric R. Blough ${ }^{a, f}$ \\ ${ }^{a}$ Center for Diagnostic Nanosystems, Marshall University, Huntington, bepartment of Public Health, \\ Marshall University, Huntington, 'Department of Pathology, ST. Mary's medical center, Huntington, \\ dDepartment of Pathology, Joan C. Edwards, School of Medicine, Marshall University, Huntington, \\ eDepartment of Bioengineering, University of Illinois, Chicago, 'Department of Pharmaceutical Sciences \\ and Research, Marshall University, Huntington, USA
}

\section{Key Words}

Cerium oxide nanoparticles • Anti-oxidant • Ischemia-reperfusion injury

\begin{abstract}
Background: Hepatic ischemia reperfusion is one the main causes for graft failure following transplantation. Although, the molecular events that lead to hepatic failure following ischemia reperfusion (IR) are diverse and complex, previous studies have shown that excessive formation of reactive oxygen species (ROS) are responsible for hepatic IR injury. Cerium oxide $\left(\mathrm{CeO}_{2}\right)$ nanoparticles have been previously shown to act as an anti-oxidant and anti-inflammatory agent. Here, we evaluated the protective effects of $\mathrm{CeO}_{2}$ nanoparticles on hepatic ischemia reperfusion injury. Methods: Male Sprague Dawley rats were randomly assigned to one of the four groups: Control, $\mathrm{CeO}_{2}$ nanoparticle only, hepatic ischemia reperfusion (IR) group and hepatic ischemia reperfusion (IR) plus $\mathrm{CeO}_{2}$ nanoparticle group (IR $+\mathrm{CeO}_{2}$ ). Partial warm hepatic ischemia was induced in left lateral and median lobes for $1 \mathrm{~h}$, followed by $6 \mathrm{~h}$ of reperfusion. Animals were sacrificed after $6 \mathrm{~h}$ of reperfusion and blood and tissue samples were collected and processed for various biochemical experiments. Results: Prophylactic treatment with $\mathrm{CeO}_{2}$ nanoparticles $\left(0.5 \mathrm{mg} / \mathrm{kg}\right.$ i.v ( $\mathrm{IR}+\mathrm{CeO}_{2}$ group)) 1 hour prior to hepatic ischemia and subsequent reperfusion injury lead to a decrease in serum levels of alanine aminotransaminase and lactate dehydrogenase at 6 hours after reperfusion. These changes were accompanied by significant decrease in hepatocyte necrosis along with reduction in several serum inflammatory markers such as macrophage derived chemokine, macrophage inflammatory protein-2, KC/GRO, myoglobin and plasminogen activator inhibitor-1. However, immunoblotting demonstrated no significant changes in the levels of apoptosis related protein markers such as bax, bcl2 and caspase 3 in IR and IR+ $\mathrm{CeO} 2$ groups at 6 hours suggesting necrosis as the main pathway for hepatocyte death. Conclusion: Taken together, these data suggest that $\mathrm{CeO}_{2}$ nanoparticles attenuate IR induced cell death and can be used as a prophylactic agent to prevent hepatic injury associated with graft failure.

(C) 2017 The Author(s)

Published by S. Karger AG, Basel

Nandini D.P.K Manne

Room 315, Prichard Hall, Department of Public Health, Marshall University, Huntington, WV 25755-1090

Tel. 304-696-3776, E-Mail manne@marshall.edu
\end{abstract}




\section{Cellular Physiology Cell Physiol Biochem 2017;42:1837-1846 \\ \begin{tabular}{l|l} 
and Biochemistry Published online: July 27, 2017 & $\begin{array}{l}\text { (c) 2017 The Author(s). Published by S. Karger AG, Basel } \\
\text { www.karger.com/cpb }\end{array}$ \\
\hline
\end{tabular} \\ Manne et al.: Cerium Oxide Nanoparticles Attenuate Hepatic Ischemia Reperfusion Injury}

\section{Introduction}

Hepatic ischemia reperfusion (IR) injury is a serious complication associated with liver transplantation and graft failure [1]. IR injury is a biphasic phenomenon that involves a temporary shut off in blood supply to the whole or part of a liver followed by sudden reperfusion [2]. Tissue injury as a result of initial hypoxic insult is enhanced and accelerated by the shear stress of sudden blood supply that disrupts the normal homeostatic mechanisms and results in generation of free radicals [3]. Increase in reactive oxygen species (ROS) have been shown to trigger a series of molecular events which involve activation of hepatic Kupffer cells, secretion of inflammatory cytokines, chemotactic factors, and recruitment of neutrophils and macrophages, all of which contribute to hepatocellular damage and death [4-6]. Previous studies have shown that Kupffer cells and neutrophils in IR injury release TNF- $\alpha$, IL- $1 \beta$ and IL- 6 which activate c-Jun N-terminal kinase 2- thereby resulting in disruption of mitochondrial membrane permeability with subsequent cytochrome c release and caspase mediated apoptotic hepatocyte death [7]. Conversely other studies have shown that IR results in hepatocyte death by necrosis although the exact mechanism still remains unclear [8]. Differences in mechanism of cell death can be attributed to the extent of hepatic ischemia (70\% vs $100 \%$ ) and the duration of ischemia applied. Nonetheless, hepatic IR is a major clinical problem that severely reduces liver graft function.

Current research on the treatment of hepatic IR injury is largely centered on the use of anti-oxidants to prevent excess ROS formation [9-11]. However, these anti-oxidant agents do not preferentially target the liver and need to be administered several times in large doses to have a clinically significant effect. As such we investigated the effect of $\mathrm{CeO}_{2}$ nanoparticles, a known anti-oxidant [12] and anti-inflammatory agent [13] for the treatment of hepatic IR injury in male Sprague Dawley rats. Previous studies have shown that $\mathrm{CeO}_{2}$ nanoparticles in therapeutic doses are non-toxic [14], relatively stable and accumulate in liver upon intravenous injection [15]. While some studies demonstrated toxicity of $\mathrm{CeO}_{2}$ nanoparticles in high doses [16], it has now been shown that the toxicity is based on whether the particles exist in $\mathrm{Ce}^{+3}$ or $\mathrm{Ce}^{+4}$ and the relative ratio of $\mathrm{Ce}^{+3} / \mathrm{Ce}^{+4}$ [17]. Furthermore, several studies have shown that $\mathrm{CeO}_{2}$ nanoparticles can be used to treat stroke [18], ovarian cancer [19], cardiomyopathy [20], sepsis [21] and obesity [22]. More recently, Oro et al., have shown that $\mathrm{CeO}_{2}$ nanoparticles attenuate steatosis and portal hypertension in rats with hepatic fibrosis [23]. Whether $\mathrm{CeO}_{2}$ nanoparticles can be used to attenuate hepatic injury caused by IR is not known. Here we found that a single prophylactic administration of $\mathrm{CeO}_{2}$ nanoparticles intravenously was effectively able to prevent hepatocyte necrosis and associated decrease in serum levels of alanine transaminase (ALT) and lactate dehydrogenase (LDH). These changes were also accompanied by decrease in hepatocyte necrosis and serum inflammatory markers; and therefore suggest $\mathrm{CeO}_{2}$ nanoparticles to be effective in treatment of hepatic IR injury.

\section{Materials and Methods}

\section{Cerium oxide nanoparticles characterization}

$\mathrm{CeO}_{2}$ nanoparticles were obtained from the U.S. Research Nanomaterials (Houston, TX) and characterized as described elsewhere [15]. Briefly $\mathrm{CeO}_{2}$ nanoparticles were characterized for their shape by field emission scanning electron microscopy (FESEM) using Hitachi S-4700 FE-SEM. Size of the nanoparticles was estimated by transmission electron microscopy using JEOL JEM-2010 operated at 200kV. Mean size of $\mathrm{CeO}_{2}$ nanoparticles in suspension was estimated by dynamic light scattering (DLS) using LB-550 DLS particle size analyzer (Horiba Scientific, Edison, NJ).

Hepatic ischemia-reperfusion injury

Ten week old male Sprague Dawley rats were purchased from Hill-Top laboratories (USA) and allowed to acclimatize for 2 weeks before use in any experiments. All surgical procedures were approved by the 


\section{Cellular Physiology Cell Physiol Biochem 2017;42:1837-1846 \\ \begin{tabular}{l|l|l} 
DOI: 10.1159/000479540 & Ond Biochemistry & $\begin{array}{l}\text { 2017 The Author(s). Published by S. Karger AG, Basel } \\
\text { www.karger.com/cpb }\end{array}$
\end{tabular} \\ Manne et al.: Cerium Oxide Nanoparticles Attenuate Hepatic Ischemia Reperfusion Injury}

institutional review board (IACUC) of Marshall University and performed in accordance to the guidelines provided by Association for Assessment and Accreditation of Laboratory Animal Care (AAALAC). Animals were housed two per cage with a 12:12 light-dark cycle and had access to food and water ad libitum. Prior to the surgical procedure, the animals were starved for $\sim 16 \mathrm{~h}$ but had access to water ad libitum. Briefly animals were deeply anesthetized under isoflurane and laparotomy was performed by a midline incision. The portal triad was identified and a partial ischemia $(\sim 70 \%)$ for $60 \mathrm{~min}$ was induced by clamping the triad that supplies blood to left lateral and median liver lobes with atraumatic bull dog clamp as described elsewhere [24]. Reperfusion was allowed by removal of the clamp for $6 \mathrm{~h}$ and the animals were sacrificed for tissue and serum collection. All animals received buprenorphine at the rate of $0.03 \mathrm{mg} / \mathrm{kg}$ s.c $20 \mathrm{~min}$ prior to ischemia induction and were also resuscitated with $5 \mathrm{ml} / \mathrm{kg}$ of normal saline i.p. Sham control $(\mathrm{n}=6)$ and ischemia-perfusion (IR) $(n=6)$ groups received $200 \mu$ of sterile deionized water via tail vein $1 \mathrm{~h}$ before surgery while cerium oxide only $\left(\mathrm{CeO}_{2}\right)(n=6)$ and ischemia-reperfusion plus cerium oxide $\left(\mathrm{IR}+\mathrm{CeO}_{2}\right)(\mathrm{n}=6)$ groups received $0.5 \mathrm{mg} / \mathrm{kg}$ of $\mathrm{CeO}_{2}$ nanoparticles via tail vein in $200 \mu \mathrm{l}$ of sterile deionized water.

\section{Evaluation of hepatocellular damage}

Liver damage was assessed by measurement of serum activity of ALT and LDH. Activity of ALT and LDH in serum were determined by a commercial kit from Sigma-Aldrich according to the manufacturer's instructions.

\section{Histopathology}

Briefly, frozen livers were sectioned $(6 \mu \mathrm{m})$ on to poly-L-lysine coated slides using Leica CM1950 cryostat. Sections from each group were stained with hematoxylin and eosin to evaluate the extent of liver damage as described elsewhere using modified Suzuki's criteria on a scale of 0-4 [25]. Briefly, slides were scored at 200× magnification to determine the percentage of necrosis as none- grade 0 , mild injury with cytoplasmic vacuolation and pyknosis-grade 1 , moderate hepatocyte damage vacuolation and pyknosisgrade 2, moderate to severe hepatocyte damage with extensive pyknosis- grade 3 and severe necrosis with hemorrhage, infiltration of neutrophils and loss of nuclei- grade 4. At least 6 random images per section were captured and evaluated using Evos XL microscope (Life technologies, Grand Island, NY).

\section{Gel electrophoresis and immunoblotting}

Approximately $150 \mathrm{mg}$ of frozen liver tissue was taken and pulverized to fine powder in liquid nitrogen. $1.4 \mathrm{ml}$ of T-PER with 1\% protease and phosphatase inhibitors (Sigma Aldrich, St. Louis, MO, USA) was added to the sample and homogenized for 1 minute. The samples were then centrifuged at 10,000 $\mathrm{xg}$ for $15 \mathrm{~min}$ at $4^{\circ} \mathrm{C}$ and the supernatant was collected. Concentration of protein in the samples was determined by $660 \mathrm{~nm}$ assay (Pierce, Rockford, IL, USA). Gel electrophoresis and immunoblotting was performed as described previously [25]. The membranes were blocked for $1 \mathrm{~h}$ in $5 \%$ non-fat dry milk in Tris-buffered saline (TBS) containing $0.05 \%$ Tween-20 (TBST) and then incubated with anti-bax, anti-bcl2, anti-cleaved caspase 3, anti-caspase 3 and anti- $\beta$-actin antibodies (Cell Signaling Technology, Danvers, MA) for $1 \mathrm{~h}$ at room temperature in $5 \%$ bovine serum albumin (BSA) in TBST. The membranes were washed thrice with TBST and incubated with secondary anti-rabbit antibody (Cell Signaling Technology, Danvers, MA) for $1 \mathrm{~h}$ in 5\% BSA in TBST. Immunoreactive signal was obtained using Supersignal West Pico Chemiluminiscent substrate (Pierce, Rockford, IL, USA) and the band intensity was quantified using Fluorchem 9900 software (Protein Simple, Santa Clara, CA). Equal loading of protein was verified by normalizing the expression of target molecule to the levels of $\beta$-actin.

\section{Multiplex immunoassay}

Multiplex immunoassay was performed to evaluate the changes in serum markers of inflammation with nanoparticle treatment. Serum samples from different groups ( $n=6 /$ group) were pooled and sent to Myriad RBM (Austin, TX) for the estimation of levels of various proteins using rodent MAP V. 3.0 as described previously [15]. Experiments were performed in triplicate for statistical analysis.

\section{Statistical analysis}

Statistical analysis was performed using SigmaPlot 12 program (Systat software Inc., San Jose, CA) to detect significant difference among various groups. A one way analysis of variance (ANOVA) with Student 
Newman Keuls posthoc analysis was performed for normally distributed data while Kruskal Wallis one way ANOVA by ranks was used for data with non-normal distribution. Results are represented as mean \pm standard error of mean (SEM). $p<0.05$ was considered to be statistically significant.

\section{Results}

Characterization of cerium oxide nanoparticles

Commercially purchased $\mathrm{CeO}_{2}$ nanoparticles were characterized to estimate the shape and size of the nanoparticles. Field emission scanning electron microscopy determined the shape to be round to spherical (Fig. 1A). Transmission electron microscopy determined the size of the nanoparticles to be in between 10-30nm (Fig. 1B). Mean hydrodynamic diameter of $\mathrm{CeO}_{2}$ nanoparticles as estimated through dynamic light scattering experiments was found to be approximately 70nanometers (Fig. 1C).

Cerium oxide nanoparticles attenuate ischemia-reperfusion induced increase in levels of alanine transaminase and lactate dehydrogenase

To investigate the therapeutic effect of $\mathrm{CeO}_{2}$ nanoparticles on hepatic ischemia reperfusion injury, we measured the serum levels of ALT and LDH that are considered to be the biomarkers of hepatocyte damage. Compared to the control animals, ischemia reperfusion injury resulted in significant increase in activity of ALT $(39.88 \pm 2.86 \mathrm{mU} / \mathrm{mL}$ vs $1195.44 \pm 187.85 \mathrm{mU} / \mathrm{mL})$ and $\mathrm{LDH}(329.03 \pm 39.12 \mathrm{mU} / \mathrm{mL}$ vs $2203.73 \pm 862.28 \mathrm{mU} / \mathrm{mL})$. On the contrary, treatment with $\mathrm{CeO}_{2}$ nanoparticles attenuated hepatic IR injured induced increase in activity of ALT $(1195.44 \pm 187.85 \mathrm{mU} / \mathrm{mL}$ vs $635.20 \pm 70.99 \mathrm{mU} / \mathrm{mL}$ ) (Fig. $2 \mathrm{~A}$, $p<0.05)$ and $\mathrm{LDH}(2203.73 \pm 862.28 \mathrm{mU} / \mathrm{mL}$ vs $792.65 \pm 109.96 \mathrm{mU} / \mathrm{mL})$ significantly (Fig. $2 \mathrm{~B}, p<0.05)$.

Cerium oxide nanoparticles attenuate ischemia-reperfusion induced hepatocyte necrosis

Previous studies have shown that hepatic IR causes severe hepatocyte necrosis leading to liver failure [26]. Similar to previous studies, we found that IR injury caused extensive hepatocyte necrosis while treatment with $\mathrm{CeO}_{2}$ nanoparticles attenuated hepatocyte necrosis significantly as evaluated by Suzuki score (Fig. 3A\&B). No hepatocyte necrosis was observed in the control or $\mathrm{CeO}_{2}$ nanoparticle alone group.

Hepatic ischemia reperfusion does not induce apoptosis in early stages

To determine the role of apoptosis in early hepatic ischemia reperfusion injury, immunoblotting was performed to evaluate the changes in apoptotic protein markers bax, bcl2, cleaved caspase 3 and caspase 3 . Interestingly no apoptosis was evident after 1 hour of partial ischemia and 6 hours of reperfusion. Similarly, $\mathrm{CeO}_{2}$ nanoparticles did not affect the expression of apoptotic proteins in both $\mathrm{CeO}_{2}$ nanoparticle group and $\mathrm{CeO}_{2}+\mathrm{IR}$ group.

A)

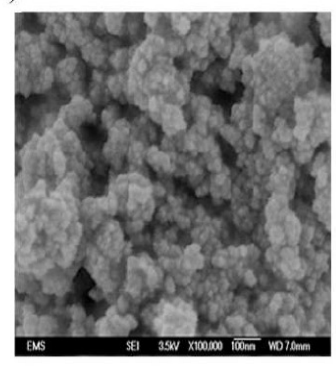

B)

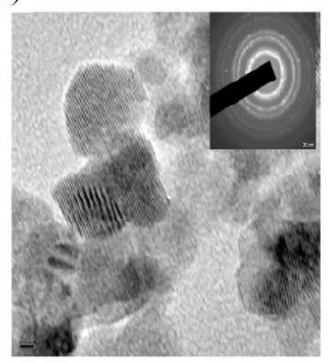

C)

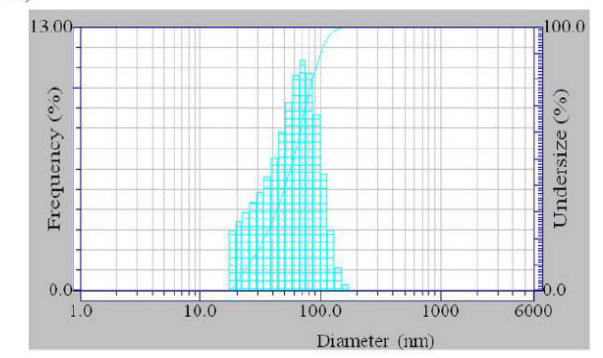

Fig 1. Characterization of $\mathrm{CeO}_{2}$ nanoparticles. (A) Field emission scanning electron microscopy (B) Transmission electron microscopy (inset- selected area diffraction) (C) Dynamic light scattering. 


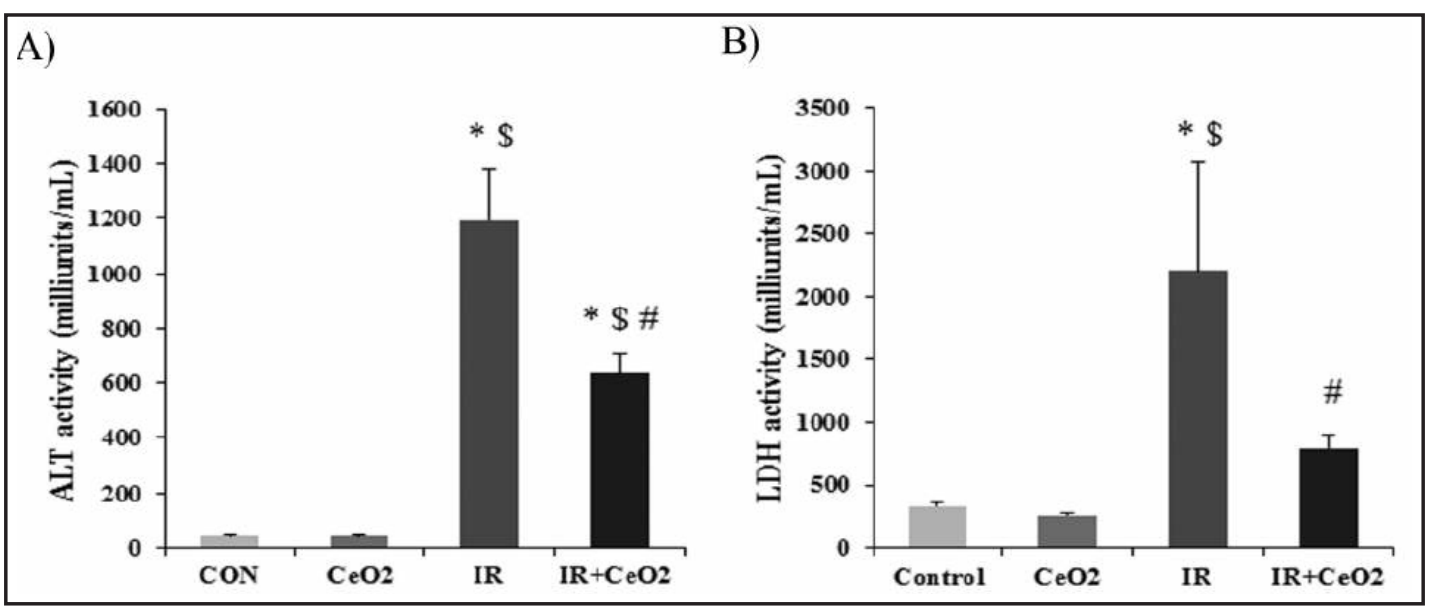

Fig 2. Effect of $\mathrm{CeO}_{2}$ nanoparticles on IR induced hepatocyte death. (A) Levels of alanine aminotransaminase in control, $\mathrm{CeO}_{2}$, IR and $\mathrm{IR}+\mathrm{CeO}_{2}$ nanoparticles at $6 \mathrm{~h}$ after reperfusion. (B) Levels of lactate dehydrogenase in control, $\mathrm{CeO}_{2}$, IR and $\mathrm{IR}+\mathrm{CeO}_{2}$ nanoparticles at $6 \mathrm{~h}$ after reperfusion. ${ }^{*} p<0.05$ compared with control group, $\$ p<0.05$ compared with $\mathrm{CeO}_{2}$ group, and $\# p<0.05$ compared with IR group (n=6/group).

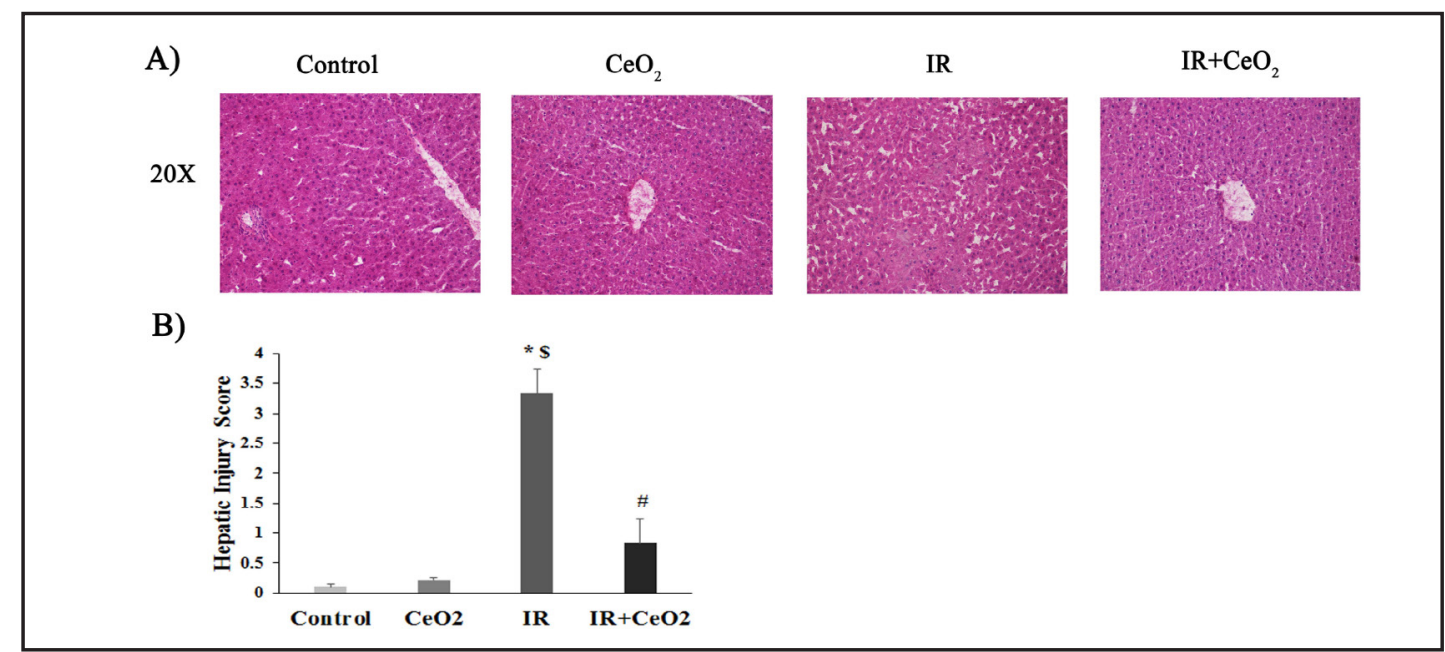

Fig 3. Effect of $\mathrm{CeO}_{2}$ nanoparticles on IR injury induced damage to hepatic cellular architecture. (A) Hematoxylin and eosin staining of liver sections after $6 \mathrm{~h}$ of reperfusion from control, $\mathrm{CeO}_{2}$ IR and $\mathrm{IR}+\mathrm{CeO}_{2}$ groups. (B) Semi-quantitative histological injury score of liver sections. ${ }^{*} p<0.05$ compared with control group, $\$ p<$ 0.05 compared with $\mathrm{CeO}_{2}$ group, and \# $p<0.05$ compared with IR group ( $\mathrm{n}=4-6 /$ group).

$\mathrm{CeO}_{2}$ nanoparticles attenuate hepatic ischemia reperfusion induced increase in serum inflammatory markers

Previous studies have shown that hepatic IR injury is associated with a marked increase in inflammatory mediators and chemotactic proteins [27]. Similar to other studies we found that IR injury lead to an increase in serum inflammatory proteins when compared to control group such as growth regulated oncogene, macrophage derived chemokine, macrophage inflammatory protein 2, myoglobin, plasminogen activator inhibitor 1 and Von Willebrand factor. Similarly, hepatic IR injury lead to an increase in serum levels of leptin and decrease in growth hormone which are shown to disrupt normal metabolism [28]. Conversely, treatment with $\mathrm{CeO}_{2}$ nanoparticles attenuated the changes in inflammatory markers and restored the values close to baseline controls. 


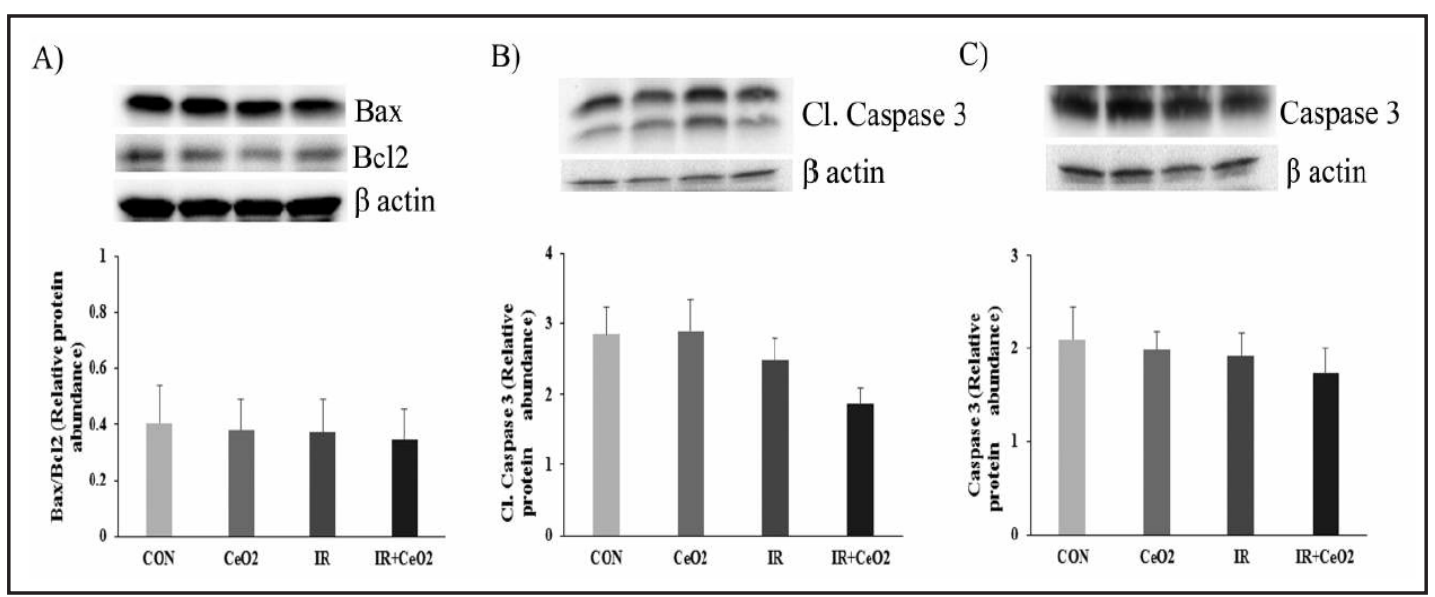

Fig 4. Apoptosis is not a major mechanism for cell death in early stages of IR injury. (A) Ratio of Bax to Bcl2 as determined by Western blotting and normalized to $\beta$-actin. (B) Levels of cleaved caspase 3 as determined by Western blotting and normalized to $\beta$-actin. (C) Levels of caspase 3 as determined by Western blotting and normalized to $\beta$-actin ( $n=6 /$ group).

\section{Discussion}

Hepatic IR is a major clinical problem that drastically reduces the function of grafts. Current treatment strategies to attenuate IR induced injury is largely supportive in nature and fails to improve graft/hepatic function. Recent studies have suggested that IR injury is primarily mediated by excess ROS formation and subsequent activation of Kupffer cells that drive the inflammatory cascade [1]. So far, studies employing the use of anti-oxidants for the treatment of hepatic IR demonstrated promising results in animal models but failed to translate the same for clinical applications [29]. One possible explanation could be the lack of sufficient levels of anti-oxidants at the major source of ROS production. Perhaps the need for targeted drug delivery that can decrease the levels of ROS in liver would result in better outcome. Recently, $\mathrm{CeO}_{2}$ nanoparticles have been employed for treatment of various inflammatory pathologies and have shown successful results [22, 30, 31]. Studies have shown that upon intravenous injection $\mathrm{CeO}_{2}$ nanoparticles remain in the circulation for brief period of time with $t_{1 / 2}$ of $7.5 \mathrm{~min}$ [32] and translocate to liver and other organs [15]. More specifically, nanoceria have been shown to be taken up by Kupffer cells with in the liver. While the exact mechanism of bioprocessing of nanoceria is still under investigation, an in vitro study by Gojova et al. indicated that it would take approximately $400 \mathrm{~h}$ for complete dissolution of a $100 \mathrm{~nm}$ particle [33]. Butterfield et al. later demonstrated that nanoceria within the liver undergo partial dissolution to form second generation nanoceria clouds that are much smaller and potentially exhibit greater activity in reduction of free radicals [34]. Due to this nature of in vivo bioprocessing of nanoceria and the inherent autocatalytic property, we hypothesized that the nanoparticles could attenuate the oxidative stress associated with hepatic IR and protect the liver without the need for multiple administration.

Studies have shown that oxidative stress drastically increases upon reperfusion [35, 36] and as such administration of $\mathrm{CeO}_{2}$ nanoparticles $1 \mathrm{~h}$ prior to ischemia would result in bioaccumulation of $\mathrm{CeO}_{2}$ nanoparticles in liver and scavenge ROS that have been generated during reperfusion. While we did not measure the levels of ROS directly, we investigated markers of increased ROS to assess the therapeutic effect of nanoparticles. Treatment with $\mathrm{CeO}_{2}$ nanoparticles $1 \mathrm{~h}$ prior to hepatic IR attenuated increases in ALT and LDH in serum which are considered to be the traditional hallmarks of hepatocellular injury (Fig. 2). Furthermore, histological analysis demonstrated the IR injury is associated with severe hepatocyte swelling, vacuolar degeneration and multiple areas of necrosis. Conversely treatment with $\mathrm{CeO}_{2}$ nanoparticles attenuated these changes and preserved normal

\section{KARGER}


A)

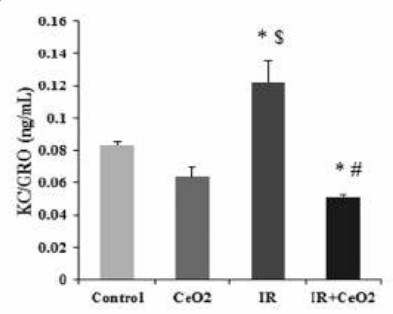

D)

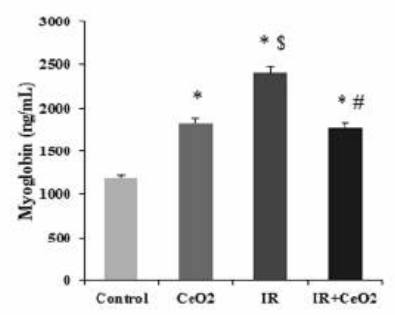

G)

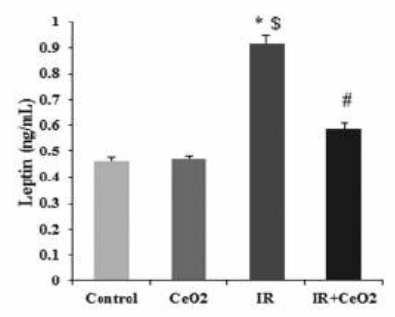

B)

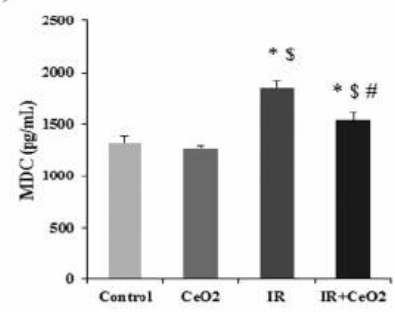

E)

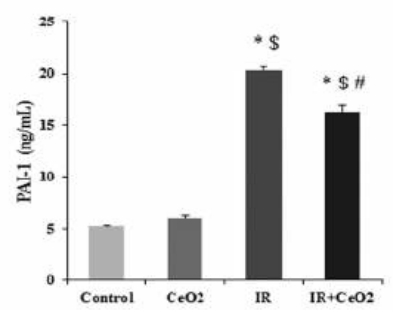

H)

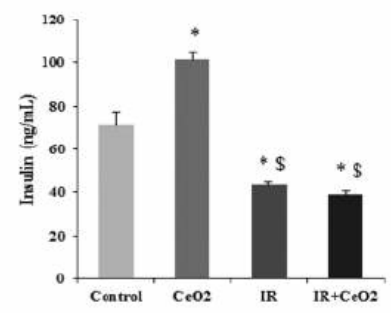

C)

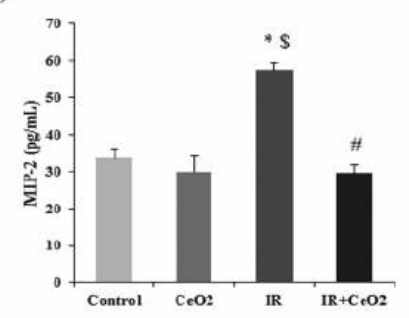

F)

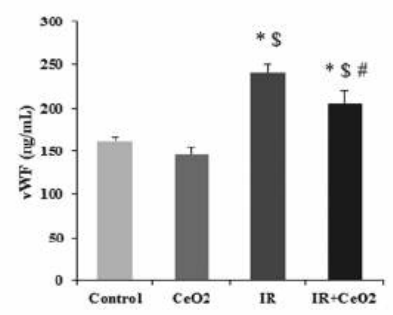

I)

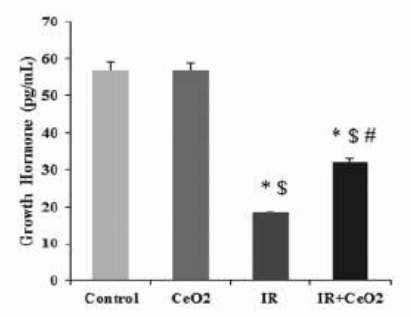

Fig 5. Effect of $\mathrm{CeO}_{2}$ nanoparticles on the expression of inflammatory cytokine and hormonal profile after $6 \mathrm{~h}$ after reperfusion. (A-I) Levels of KC/GRO, MDC, MIP-2, myoglobin, PAI-1, vWF, leptin, insulin and growth hormone in control, $\mathrm{CeO}_{2}, \mathrm{IR}$ and $\mathrm{IR}+\mathrm{CeO}_{2}$ nanoparticles groups. ${ }^{*} p<0.05$ compared with control group, $\$ p$ $<0.05$ compared with $\mathrm{CeO}_{2}$ group, and $\# p<0.05$ compared with IR group (n=6/group).

hepatocellular architecture (Fig. 3). These changes demonstrate that $\mathrm{CeO}_{2}$ nanoparticles are effective in attenuating ROS induced cell death and therefore protect hepatocytes from IR induced damage.

There is a growing body of evidence that indicates apoptosis is a leading mechanism of hepatocyte death in IR injury besides necrosis [37]. As such we investigated the changes in protein levels of bax, bcl 2 and cleavage of caspase 3 that are involved in intrinsic pathway of apoptosis, and did not find any evidence of changes in bax/bcl2 ratio across all groups nor increases in levels of cleaved caspase 3 (Fig. 4) which is in agreement with previous studies [38]. Why different studies arrive at different findings is unclear but it might be due to the differences in animal model used, starvation before IR, percentage of ischemia ( $70 \%$ vs $100 \%$ ), duration of ischemia (45min vs $60 \mathrm{~min}$ vs $90 \mathrm{~min}$ ) and the time allowed for reperfusion. Moreover, it has been previously shown that quantitatively apoptosis in warm IR never exceeds greater $2 \%$ of hepatocytes at risk and that necrosis accounts to $90 \%$ of cell death. Since many necrotic cells are also TUNEL positive, one could misinterpret apoptosis as the major cause of cell death in hepatic IR [8].

Given the ability of $\mathrm{CeO}_{2}$ nanoparticles to scavenge ROS [39] that are implicated in the secretion of inflammatory cytokines, we next examined whether nanoparticles could attenuate the increase in inflammatory cytokines associated with hepatic IR injury. Previous studies KARGER 


\section{Cellular Physiology Cell Physiol Biochem 2017;42:1837-1846

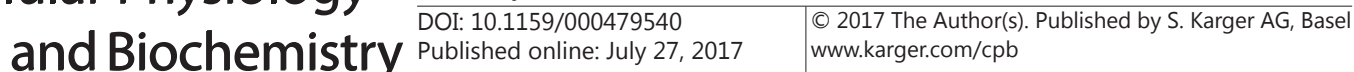

have indicated the involvement of neutrophils and lymphocytes in IR induced cell death [40] and that therapeutic interventions to attenuate the excessive inflammatory response from these cells during IR are needed to protect the hepatocytes. Growth regulated oncogene and macrophage inflammatory protein 2 are major chemoattractants for neutrophils [41] while macrophage derived chemokine is a chemoattractant for lymphocytes [42]. Similarly, other proteins such as plasminogen activator inhibitor 1, myoglobin and Von Willebrand factor are implicated in hepatic IR injury [43-45]. Therapeutic interventions aimed at decreasing the levels of chemoattractant and inflammatory mediators are useful in attenuating overall hepatic IR induced cell death. As expected, $\mathrm{CeO}_{2}$ nanoparticles attenuated IR induced increases in levels of these inflammatory mediators (Fig 5). Other studies have shown that IR injury also deregulates the metabolic homeostasis and is associated with increased levels of leptin [28]. Increased levels of leptin during IR suggest that leptin confers protection against host inflammatory response [46]. Similarly, hepatic IR injury is also associated with decrease in levels of growth hormone (Fig. 5) that has been shown to promote synthesis of cytoprotective insulin-like growth factor- 1 [47]. Conversely $\mathrm{CeO}_{2}$ nanoparticles attenuated IR induced increase in leptin and decrease in growth hormone (Fig. 5). Studies have shown that hepatic IR is also associated with decreased levels of insulin and induced insulin resistance [48]. We sought to investigate whether $\mathrm{CeO}_{2}$ nanoparticle treatment would improve the levels of circulating insulin. However, treatment did not improve the levels of insulin which suggest an alternate pathway for decreased levels in hepatic IR and that $\mathrm{CeO}_{2}$ nanoparticles had no effect on this molecular pathway. Taken together the data suggest that prophylactic treatment with $\mathrm{CeO}_{2}$ nanoparticles could serve as a novel therapeutic strategy for the treatment of hepatic ischemia reperfusion injury.

\section{Acknowledgements}

This work was supported in part from department of energy (DOE) grant (DE-PS0209ER-01 to E.R.B). TS would like to acknowledge NSF CAREER award \# 1564950.

\section{Disclosure Statement}

The authors declare that they have no conflict of interest.

\section{References}

- Li J, Wang F, Xia Y, Dai W, Chen K, Li S, Liu T, Zheng Y, Wang J, Lu W, Zhou Y, Yin Q, Lu J, Zhou Y, Guo C: Astaxanthin Pretreatment Attenuates Hepatic Ischemia Reperfusion-Induced Apoptosis and Autophagy via the ROS/MAPK Pathway in Mice. Mar Drugs 2015;13:3368-3387.

2 Peralta C, Jimenez-Castro MB, Gracia-Sancho J: Hepatic ischemia and reperfusion injury: effects on the liver sinusoidal milieu. J Hepatol 2013;59:1094-1106.

-3 Jaeschke H: Molecular mechanisms of hepatic ischemia-reperfusion injury and preconditioning. Am J Physiol Gastrointest Liver Physiol 2003;284:G15-26.

-4 Bhogal RH, Curbishley SM, Weston CJ, Adams DH, Afford SC: Reactive oxygen species mediate human hepatocyte injury during hypoxia/reoxygenation. Liver Transpl 2010;16:1303-1313.

-5 Hochhauser E, Lahat E, Sultan M, Pappo O, Waldman M, Sarne Y, Shainberg A, Gutman M, Safran M, Ben Ari Z: Ultra Low Dose Delta 9-Tetrahydrocannabinol Protects Mouse Liver from Ischemia Reperfusion Injury. Cell Physiol Biochem 2015;36:1971-1981.

6 Zhang X, Tan Z, Wang Y, Tang J, Jiang R, Hou J, Zhuo H, Wang X, Ji J, Qin X, Sun B: PTPRO-associated hepatic stellate cell activation plays a critical role in liver fibrosis. Cell Physiol Biochem 2015;35:885-898.

7 Uehara T, Bennett B, Sakata ST, Satoh Y, Bilter GK, Westwick JK, Brenner DA: JNK mediates hepatic ischemia reperfusion injury. J Hepatol 2005;42:850-859. 


\section{Cellular Physiology Cell Physiol Biochem 2017;42:1837-1846 \begin{tabular}{l|l} 
and Biochemistry & DOI: 10.1159/000479540 \\
(c) 2017 The Author(s). Published by S. Karger AG, Basel \\
www.karger.com/cpb
\end{tabular}

8 Jaeschke H, Lemasters JJ: Apoptosis versus oncotic necrosis in hepatic ischemia/reperfusion injury. Gastroenterology 2003;125:1246-1257.

-9 Bonatsos V, Kappas I, Birbas K, Vlachodimitropoulos D, Toutouzas K, Karampela E, Syrmos N, Bonatsos G, Papalois AE: Effects of U-74389G (21-Lazaroid) and Ascorbic Acid on Liver Recovery After Acute Ischemia and Reperfusion in Rats. In Vivo 2015;29:585-594.

10 Liu A, Huang L, Fan H, Fang H, Yang Y, Liu S, Hu J, Hu Q, Dirsch O, Dahmen U: Baicalein pretreatment protects against liver ischemia/reperfusion injury via inhibition of NF-kappaB pathway in mice. Int Immunopharmacol 2015;24:72-79.

11 Ramalho LN, Pasta AA, Terra VA, Augusto M, Sanches SC, Souza-Neto FP, Cecchini R, Gulin F, Ramalho FS: Rosmarinic acid attenuates hepatic ischemia and reperfusion injury in rats. Food Chem Toxicol 2014;74:270-278.

12 Caputo F, De Nicola M, Sienkiewicz A, Giovanetti A, Bejarano I, Licoccia S, Traversa E, Ghibelli L: Cerium oxide nanoparticles, combining antioxidant and UV shielding properties, prevent UV-induced cell damage and mutagenesis. Nanoscale 2015;7:15643-15656.

13 Arya A, Sethy NK, Singh SK, Das M, Bhargava K: Cerium oxide nanoparticles protect rodent lungs from hypobaric hypoxia-induced oxidative stress and inflammation. Int J Nanomedicine 2013;8:4507-4520.

14 Hirst SM, Karakoti A, Singh S, Self W, Tyler R, Seal S, Reilly CM: Bio-distribution and in vivo antioxidant effects of cerium oxide nanoparticles in mice. Environ Toxicol 2013;28:107-118.

15 Manne ND, Arvapalli R, Nepal N, Thulluri S, Selvaraj V, Shokuhfar T, He K, Rice KM, Asano S, Maheshwari M, Blough ER: Therapeutic Potential of Cerium Oxide Nanoparticles for the Treatment of Peritonitis Induced by Polymicrobial Insult in Sprague-Dawley Rats. Crit Care Med 2015;43:e477-489.

-16 Tseng MT, Fu Q, Lor K, Fernandez-Botran GR, Deng ZB, Graham U, Butterfield DA, Grulke EA, Yokel RA: Persistent hepatic structural alterations following nanoceria vascular infusion in the rat. Toxicol Pathol 2014;42:984-996.

17 Dunnick KM, Pillai R, Pisane KL, Stefaniak AB, Sabolsky EM, Leonard SS: The Effect of Cerium Oxide Nanoparticle Valence State on Reactive Oxygen Species and Toxicity. Biol Trace Elem Res 2015;166:96-107.

18 Estevez AY, Pritchard S, Harper K, Aston JW, Lynch A, Lucky JJ, Ludington JS, Chatani P, Mosenthal WP, Leiter JC, Andreescu S, Erlichman JS: Neuroprotective mechanisms of cerium oxide nanoparticles in a mouse hippocampal brain slice model of ischemia. Free Radic Biol Med 2011;51:1155-1163.

19 Giri S, Karakoti A, Graham RP, Maguire JL, Reilly CM, Seal S, Rattan R, Shridhar V: Nanoceria: a rare-earth nanoparticle as a novel anti-angiogenic therapeutic agent in ovarian cancer. PLoS One 2013;8:e54578.

20 Niu J, Azfer A, Rogers LM, Wang X, Kolattukudy PE: Cardioprotective effects of cerium oxide nanoparticles in a transgenic murine model of cardiomyopathy. Cardiovasc Res 2007;73:549-559.

21 Manne ND, Arvapalli R, Nepal N, Shokuhfar T, Rice KM, Asano S, Blough ER: Cerium oxide nanoparticles attenuate acute kidney injury induced by intra-abdominal infection in Sprague-Dawley rats. J Nanobiotechnology 2015;13:75.

22 Rocca A, Moscato S, Ronca F, Nitti S, Mattoli V, Giorgi M, Ciofani G: Pilot in vivo investigation of cerium oxide nanoparticles as a novel anti-obesity pharmaceutical formulation. Nanomedicine 2015;11:1725-1734.

23 Oro D, Yudina T, Fernandez-Varo G, Casals E, Reichenbach V, Casals G, Gonzalez de la Presa B, Sandalinas S, Carvajal S, Puntes V, Jimenez W: Cerium oxide nanoparticles reduce steatosis, portal hypertension and display anti-inflammatory properties in rats with liver fibrosis. J Hepatol 2015;10.1016/j.jhep.2015.10.020

24 Zhang XF, Zhang R, Huang L, Wang PX, Zhang Y, Jiang DS, Zhu LH, Tian S, Zhang XD, Li H: TRAF1 is a key mediator for hepatic ischemia/reperfusion injury. Cell Death Dis 2014;5:e1467.

25 Zhang C, Liao Y, Li Q Chen M, Zhao Q Deng R, Wu C, Yang A, Guo Z, Wang D, He X: Recombinant adiponectin ameliorates liver ischemia reperfusion injury via activating the AMPK/eNOS pathway. PLoS One 2013;8:e66382.

26 Liu QS, Cheng ZW, Xiong JG, Cheng S, He XF, Li XC: Erythropoietin pretreatment exerts anti-inflammatory effects in hepatic ischemia/reperfusion-injured rats via suppression of the TLR2/NF-kappaB pathway. Transplant Proc 2015;47:283-289.

27 Lentsch AB, Kato A, Yoshidome H, McMasters KM, Edwards MJ: Inflammatory mechanisms and therapeutic strategies for warm hepatic ischemia/reperfusion injury. Hepatology 2000;32:169-173.

28 Lin J, Gao XN, Yan GT, Xue H, Hao XH, Wang LH: Endogenous leptin fluctuates in hepatic ischemia/ reperfusion injury and represents a potential therapeutic target. World J Gastroenterol 2010;16:54245434. 


\section{Cellular Physiology Cell Physiol Biochem 2017;42:1837-1846 \begin{tabular}{l|l} 
DOI: 10.1159/000479540 & $\begin{array}{l}\text { O 2017 The Author(s). Published by S. Karger AG, Basel } \\
\text { www.karger.com/cpb }\end{array}$ \\
\hline
\end{tabular}

29 Jaeschke H, Woolbright BL: Current strategies to minimize hepatic ischemia-reperfusion injury by targeting reactive oxygen species. Transplant Rev (Orlando) 2012;26:103-114.

-30 Pesic M, Podolski-Renic A, Stojkovic S, Matovic B, Zmejkoski D, Kojic V, Bogdanovic G, Pavicevic A, Mojovic M, Savic A, Milenkovic I, Kalauzi A, Radotic K: Anti-cancer effects of cerium oxide nanoparticles and its intracellular redox activity. Chem Biol Interact 2015;232:85-93.

-31 Estevez AY, Erlichman JS: The potential of cerium oxide nanoparticles (nanoceria) for neurodegenerative disease therapy. Nanomedicine (Lond) 2014;9:1437-1440.

-32 Yokel RA, Hussain S, Garantziotis S, Demokritou P, Castranova V, Cassee FR: The Yin: An adverse health perspective of nanoceria: uptake, distribution, accumulation, and mechanisms of its toxicity. Environ Sci Nano 2014;1:406-428.

-33 Gojova A, Lee JT, Jung HS, Guo B, Barakat AI, Kennedy IM: Effect of cerium oxide nanoparticles on inflammation in vascular endothelial cells. Inhal Toxicol 2009;21 Suppl 1:123-130.

-34 Graham UM, Tseng MT, Jasinski JB, Yokel RA, Unrine JM, Davis BH, Dozier AK, Hardas SS, Sultana R, Grulke EA, Allan Butterfield D: In Vivo Processing of Ceria Nanoparticles inside Liver: Impact on Free-Radical Scavenging Activity and Oxidative Stress. Chempluschem 2014;79:1083-1088.

- 35 Montalvo-Jave EE, Escalante-Tattersfield T, Ortega-Salgado JA, Pina E, Geller DA: Factors in the pathophysiology of the liver ischemia-reperfusion injury. J Surg Res 2008;147:153-159.

-36 Xu Z, Yu J, Wu J, Qi F, Wang H, Wang Z, Wang Z: The Effects of Two Anesthetics, Propofol and Sevoflurane, on Liver Ischemia/Reperfusion Injury. Cell Physiol Biochem 2016;38:1631-1642.

-37 Yang M, Antoine DJ, Weemhoff JL, Jenkins RE, Farhood A, Park BK, Jaeschke H: Biomarkers distinguish apoptotic and necrotic cell death during hepatic ischemia/reperfusion injury in mice. Liver Transpl 2014;20:1372-1382.

-38 Gujral JS, Bucci TJ, Farhood A, Jaeschke H: Mechanism of cell death during warm hepatic ischemiareperfusion in rats: apoptosis or necrosis? Hepatology 2001;33:397-405.

39 Das M, Patil S, Bhargava N, Kang JF, Riedel LM, Seal S, Hickman JJ: Auto-catalytic ceria nanoparticles offer neuroprotection to adult rat spinal cord neurons. Biomaterials 2007;28:1918-1925.

40 Jaeschke H: Mechanisms of Liver Injury. II. Mechanisms of neutrophil-induced liver cell injury during hepatic ischemia-reperfusion and other acute inflammatory conditions. Am J Physiol Gastrointest Liver Physiol 2006;290:G1083-1088.

41 Lentsch AB, Yoshidome H, Cheadle WG, Miller FN, Edwards MJ: Chemokine involvement in hepatic ischemia/reperfusion injury in mice: roles for macrophage inflammatory protein-2 and KC. Hepatology 1998;27:1172-1177.

-42 Richter JR, Sutton JM, Belizaire RM, Friend LA, Schuster RM, Johannigman TA, Miller SG, Lentsch AB, Pritts TA: Macrophage-derived chemokine (CCL22) is a novel mediator of lung inflammation following hemorrhage and resuscitation. Shock 2014;42:525-531.

43 Inoue K, Sugawara Y, Kubota K, Takayama T, Makuuchi M: Induction of type 1 plasminogen activator inhibitor in human liver ischemia and reperfusion. J Hepatol 2000;33:407-414.

44 Urisono Y, Matsui H, Kasuda S, Ono S, Nishio K, Akiyama M, Miyata T, Okuchi K, Sugimoto M: Functional Relevance of Von Willebrand Factor in Mouse Model of Hepatic Ischemia- Reperfusion Injury. Blood 2016;128:1356-1356.

-45 Nitta T, Xundi X, Hatano E, Yamamoto N, Uehara T, Yoshida M, Harada N, Honda K, Tanaka A, Sosnowski D, Chance B, Yamaoka Y: Myoglobin gene expression attenuates hepatic ischemia reperfusion injury. J Surg Res 2003;110:322-331.

-46 Ustun YB, Koksal E, Kaya C, Sener EB, Aksoy A, Yarim G, Kabak Y, Gulbahar Y: The effects of dexketoprofen on endogenous leptin and lipid peroxidation during liver ischemia reperfusion injury. Int Surg 2014;99:757-763.

47 Casillas-Ramirez A, Zaouali A, Padrissa-Altes S, Ben Mosbah I, Pertosa A, Alfany-Fernandez I, BintanelMorcillo M, Xaus C, Rimola A, Rodes J, Rosello-Catafau J, Peralta C: Insulin-like growth factor and epidermal growth factor treatment: new approaches to protecting steatotic livers against ischemia-reperfusion injury. Endocrinology 2009;150:3153-3161.

- 48 Liu C, Wang X, Chen Z, Zhang L, Wu Y, Zhang Y: Hepatic ischemia-reperfusion induces insulin resistance via down-regulation during the early steps in insulin signaling in rats. Transplant Proc 2008;40:3330-3334. 